\title{
Quantification of Acoustic Scattering Prediction Uncertainty for Aircraft System Noise Assessment
}

\author{
Casey L. Burley, Russell H. Thomas \\ NASA Langley Research Center, Hampton, VA, USA \\ And \\ Yueping Guo \\ NEAT Consulting \\ Seal Beach, CA, USA
}

$22^{\text {nd }}$ AIAA/CEAS Aeroacoustics Conference

Lyon, France

June 1, 2016

AIAA Paper 2016-3041 


\section{Acknowledgement}

The authors would like to thank

- The NASA Environmentally Responsible Aviation Project for funding this work 


\section{Outline}

- Background and Motivation

- $\quad$ ERA N+2 Vehicle Concepts

- Assessment Objective

- $\quad$ System Noise Assessment

- Acoustic Scattering Prediction: PAA-effect

- Quantification of Prediction Uncertainty

- Reference data prediction test method

- Results for system noise assessment

- Concluding Remarks 


\section{ERA Project Goal}

NASA Subsonic Transport Metrics

V2013.1

\begin{tabular}{|c|c|c|c|}
\hline \multirow{2}{*}{$\begin{array}{c}\text { TECHNOLOGY } \\
\text { BENEFITS* }\end{array}$} & \multicolumn{3}{|c|}{$\begin{array}{c}\text { TECHNOLOGY GENERATIONS } \\
\text { (Technology Readiness Level = 4-6) }\end{array}$} \\
\cline { 2 - 4 } & $\mathrm{N}+1(2015)$ & $\mathrm{N}+2\left(2020^{\star *}\right)$ & $\mathrm{N+3}(2025)$ \\
\hline $\begin{array}{c}\text { Noise } \\
\text { (cum margin rel. to Stage 4) }\end{array}$ & $-32 \mathrm{~dB}$ & $-42 \mathrm{~dB}$ & $-80 \%$ \\
\hline $\begin{array}{c}\text { LTO NOx Emissions } \\
\text { (rel. to CAEP 6) }\end{array}$ & $-60 \%$ & $-75 \%$ & $-80 \%$ \\
\hline $\begin{array}{c}\text { Cruise NOx Emissions } \\
\text { (rel. to 2005 best in class) }\end{array}$ & $-55 \%$ & $-70 \%$ & $-60 \%$ \\
\hline $\begin{array}{c}\text { Aircraft Fuel/Energy Consumption } \\
\text { (rel. to 2005 best in class) }\end{array}$ & $-33 \%$ & $-50 \%$ & -12013.1 \\
\hline
\end{tabular}

* Projected benefits once technologies are matured and implemented by industry. Benefits vary by vebicle size and mission. $\mathrm{N}+1$ and $\mathrm{N}+3$ values are referenced to a 737-800 with CFM56-7B engines, $N+2$ values are referenced to a 777-200 with GE90 engines

** ERA's time-phased approach includes advancing "long-pole" technologies to TRL 6 by 2015

¥ $\mathrm{CO} 2$ emission benefits dependent on life-cycle CO2e per MJ for fuel and/or energy source used

The ERA Project's goal is to identify and mature technologies and advanced configurations that, when integrated, can simultaneously meet the N+2 noise, LTO NOx, and fuel burn reduction metrics 


\section{Noise Certification Measurement Points}

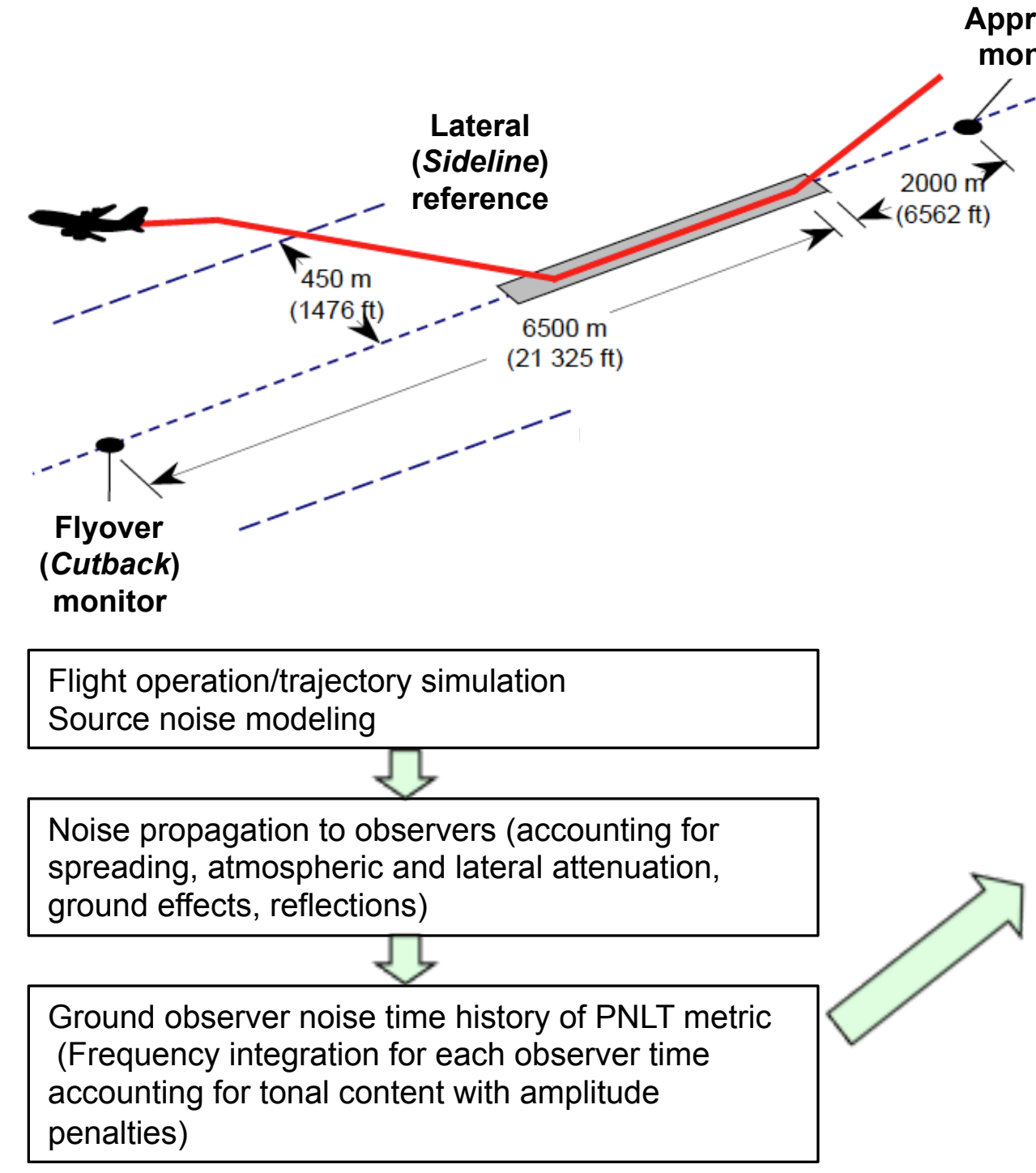

PNLT $=$ tone corrected perceived noise level

\section{Noise certification points}

- Lateral (Sideline)

- Flyover with Cutback

- Approach

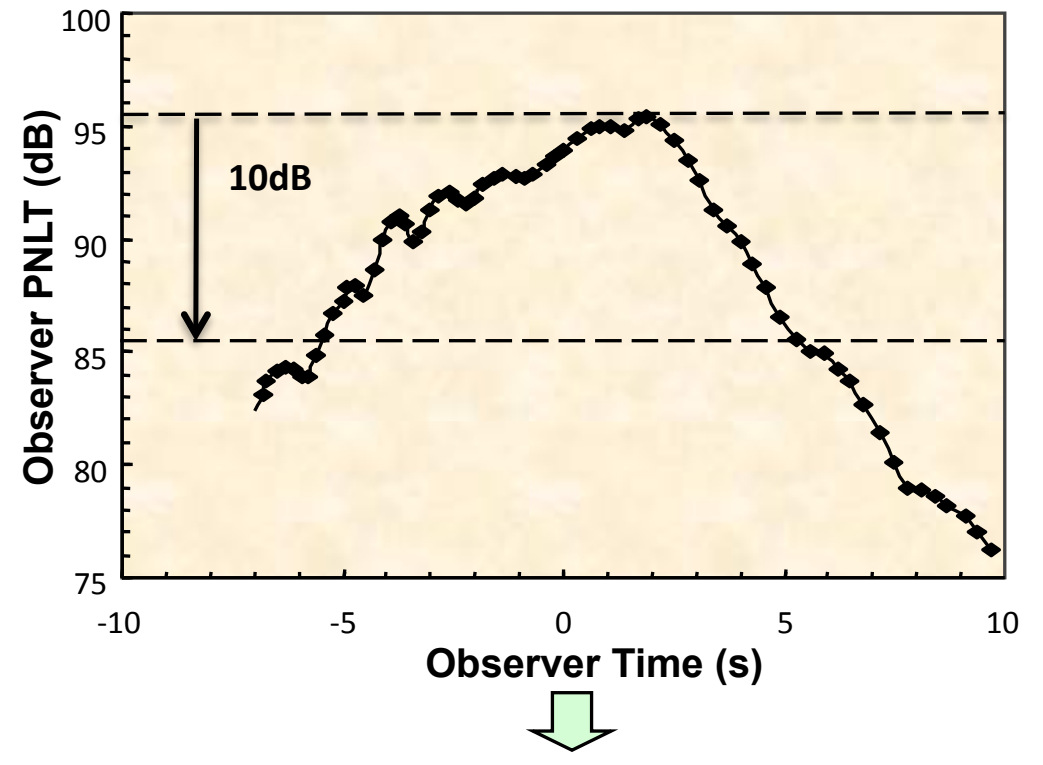

Time integration to Effective Perceived Noise Level: EPNL 


\section{ERA System Noise Prediction Process}

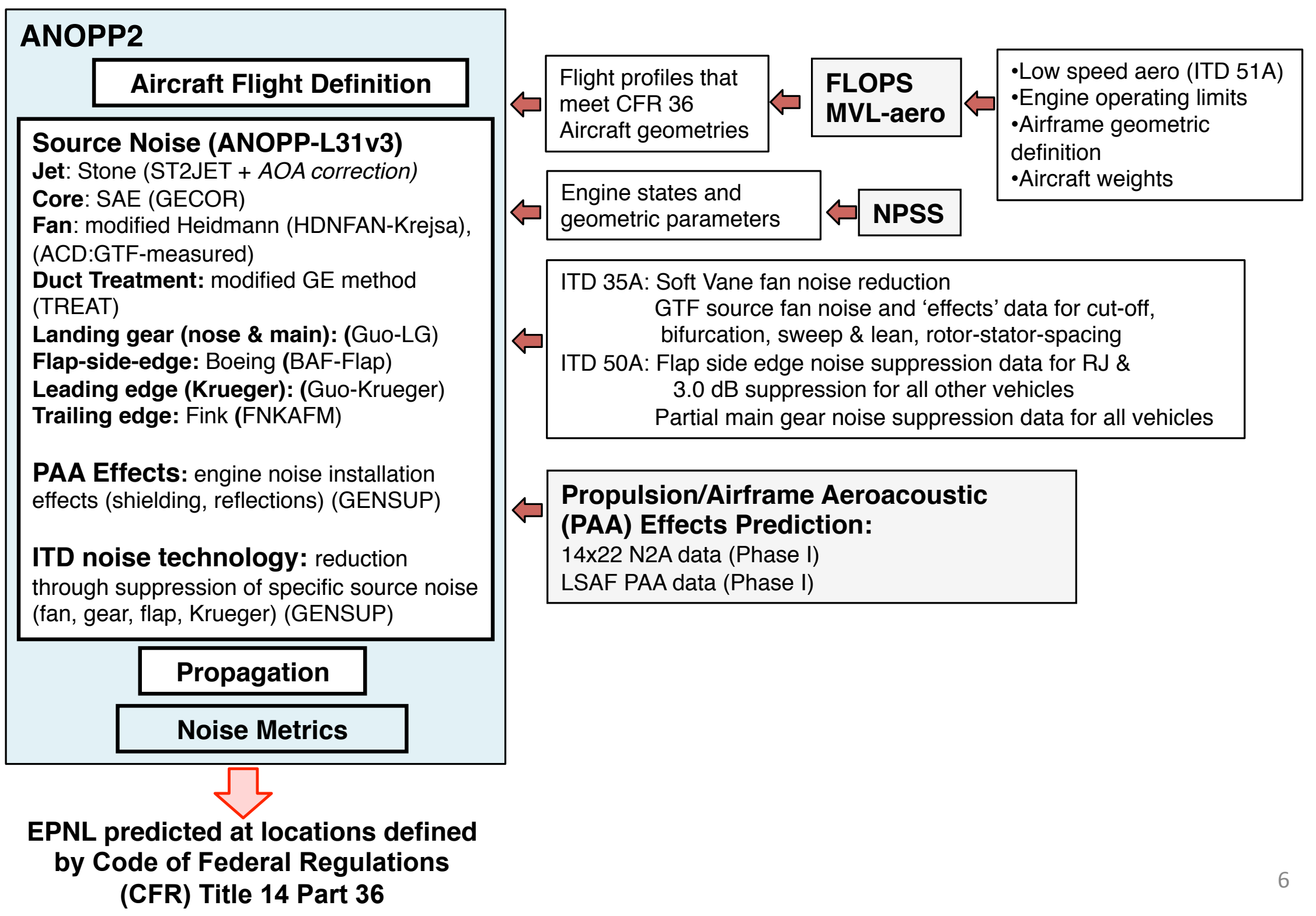




\section{Vehicle Assessment - Advanced N+2 (2025) Large Twin-Aisle Concepts}

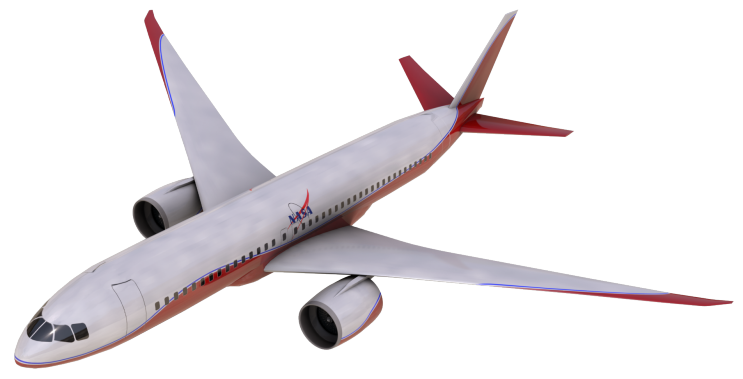

T+W301-GTF (Tube-and-Wing)

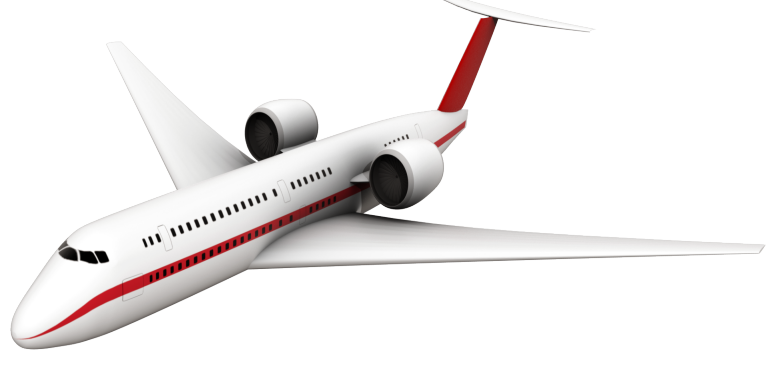

MFN301-GTF Mid-Fuselage Nacelle

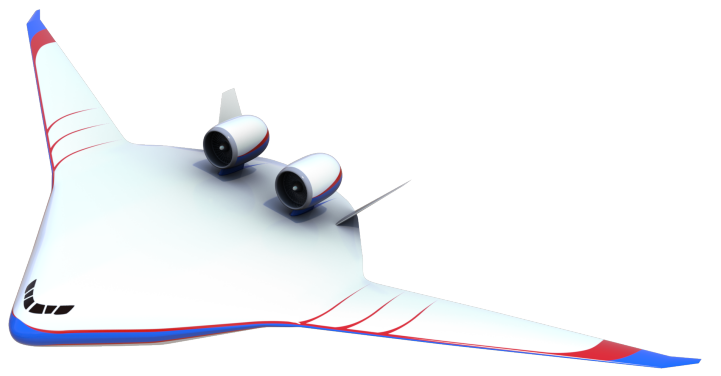

HWB301-GTF Hybrid Wing Body

\begin{tabular}{|l|l|l|l|}
\hline & T+W301-GTF & MFN301-GTF & HWB301-GTF \\
\hline TOGW (Ibs) & 570,533 & 540,837 & 534,491 \\
\hline Payload (lbs) & 118,100 & 118,100 & 118,100 \\
\hline Design Range $(\mathrm{nm})$ & 7500 & 7500 & 7500 \\
\hline
\end{tabular}

Same mission, different configuration and aero-performance 


\section{Aircraft Cumulative Noise Results}

\section{$\mathrm{N}+2$ includes:}

UHB GTF or DD engines

Light weight structures

Single element trailing edge flap

Leading edge Krueger flap

Configuration dependent PAA effects

Multi-degree of freedom duct liners (MDOF)

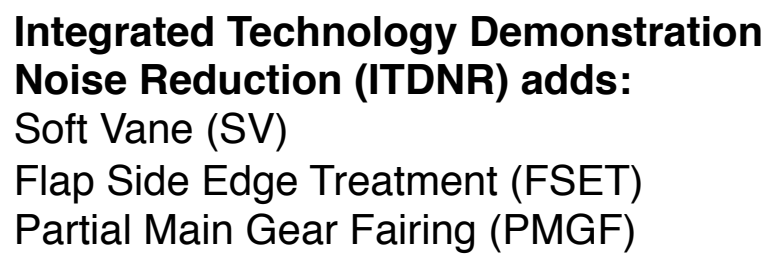

Flap Side Edge Treatment (FSET)

Partial Main Gear Fairing (PMGF)

ITDNR combined 0.9 to $2.5 \mathrm{~dB}$ noise reduction

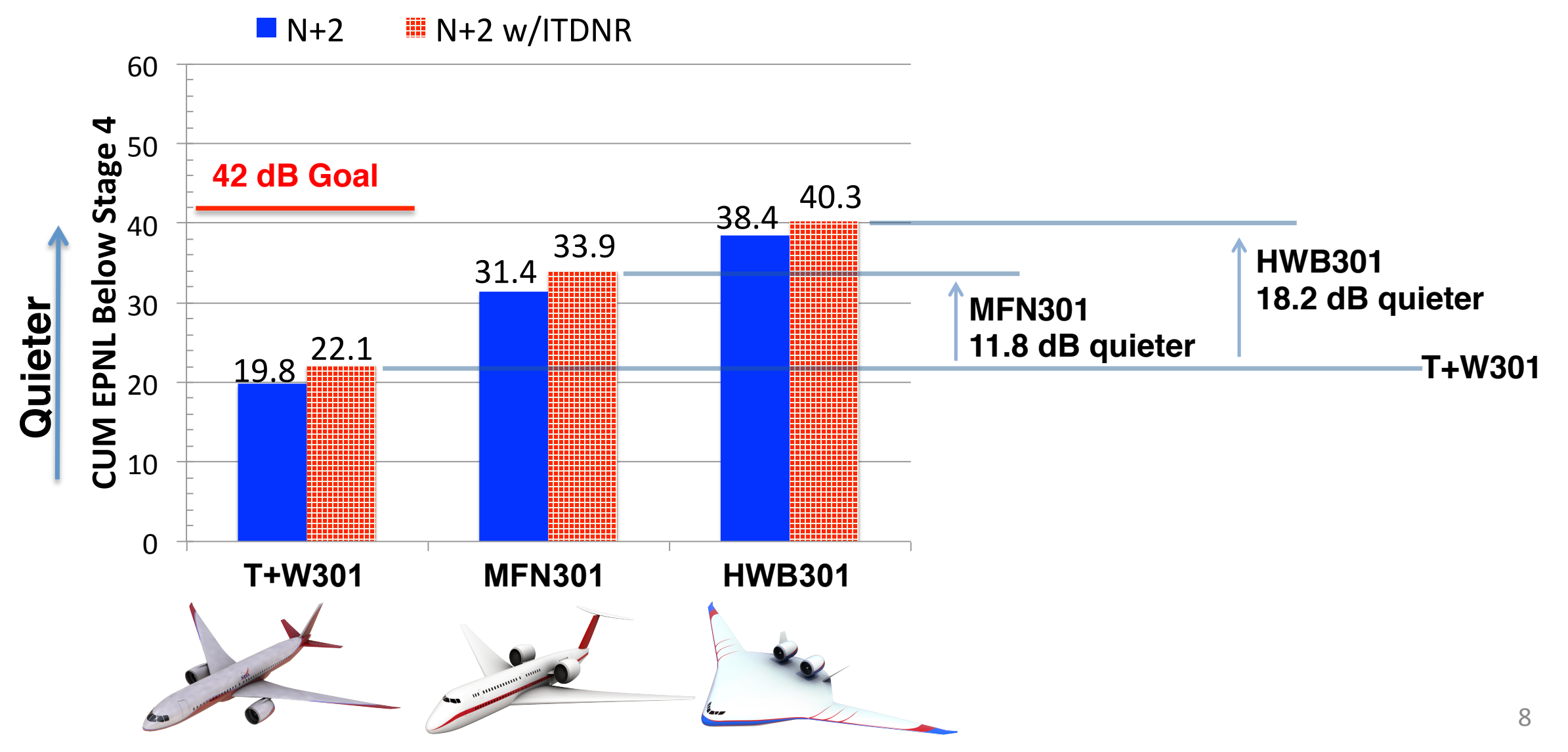




\section{Acoustic Scattering Prediction of Propulsion Airframe Aeroacoustic (PAA) Interaction Effects}

- Multi-parameter analysis of the most closely matched datasets coupled with theoretical analysis, computational and analytical modeling.

- Datasets

- LSAF and 14x22 aeroacoustic test campaigns

- HWB and conventional tube-and-wing configurations with variations in source noise definition: distributed and point broadband sources, jet

- Operational parameters defined for approach and takeoff conditions

- Acoustic data as function of configuration, power condition, frequency and both polar \& azimuthal directivity.

- Computational and analytical modeling

- Account for effects not fully represented in the datasets such as reflections from horizontal tails, or specific full aircraft configurations with multiple engines

- Extend frequency and directivity angle definitions to required full-scale ranges 


\section{Shielding Characteristics}

- Angular zones

- Insonified: slight noise increase due to edge diffraction

- Partially insonified: noise reduction by half of the direct radiation but slight increase due to diffraction

- Shadow: no direct radiation and diffraction as noise floor

- Boundaries of angular zones predicted by geometry and vary with engine/wing configuration

- Diffraction amplitudes determined by source/edge distance and frequency

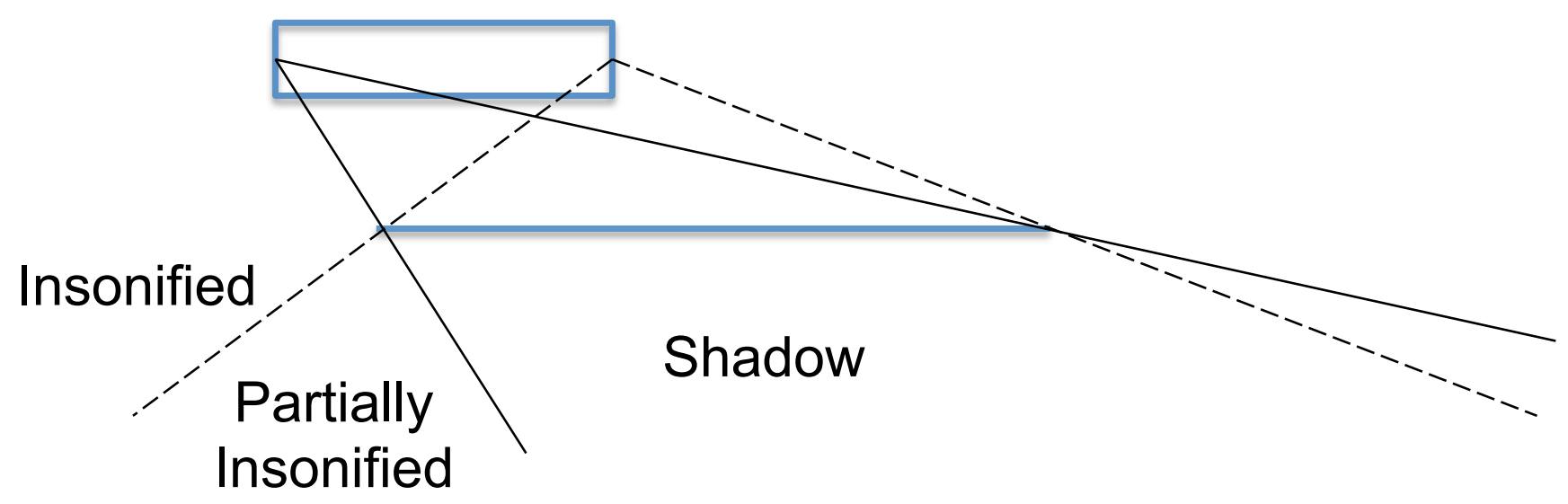




\section{Noise Scattering Map Prediction}

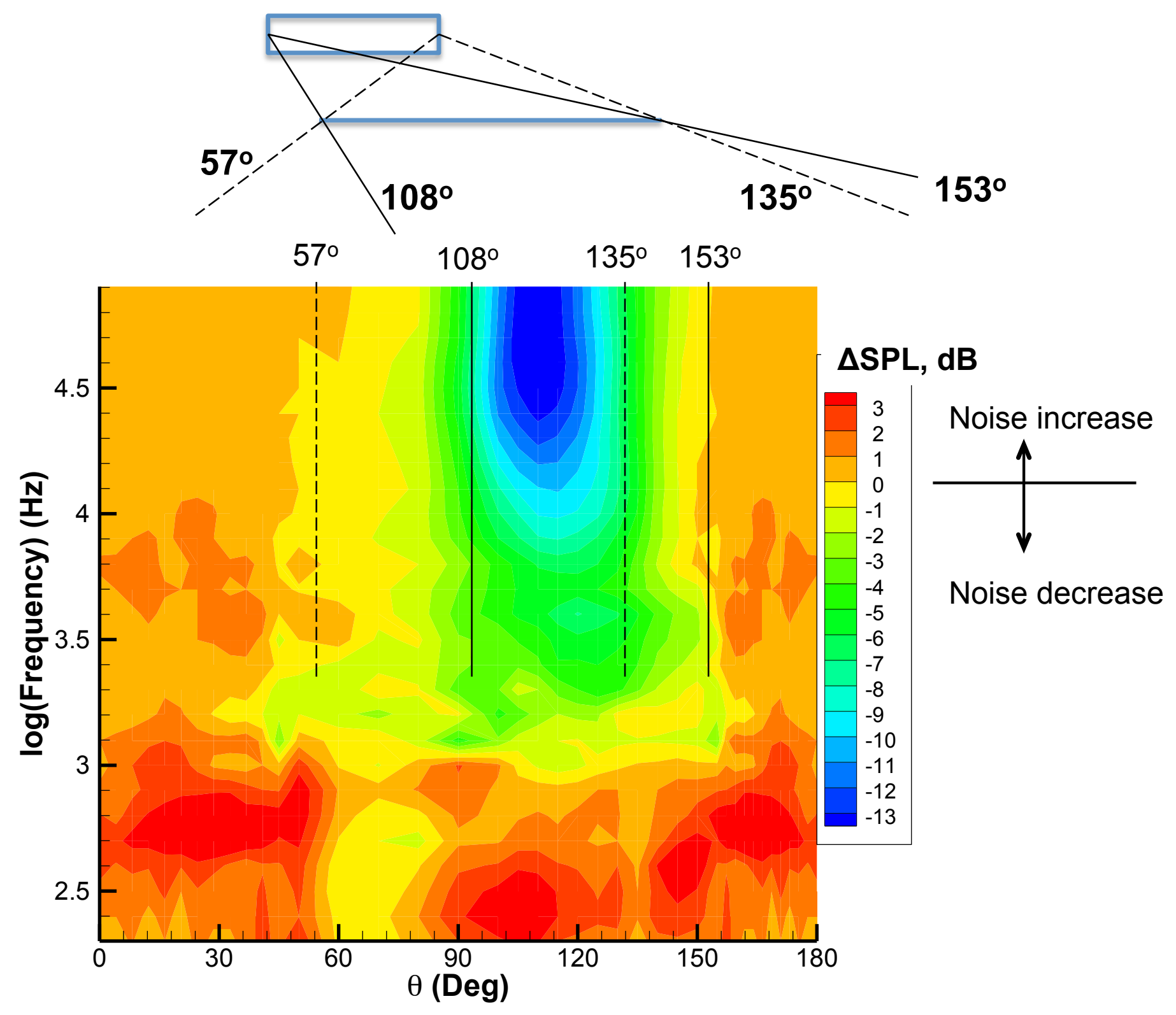




\section{Acoustic Scattering Prediction of Propulsion Airframe Aeroacoustic (PAA) Interaction Effects}

- Modification to engine source noise components

- "Suppression/Attenuation"

$$
S(f, \theta, \phi)=\frac{P_{r m s}^{2}(f, \theta, \phi)_{\text {shielded }}}{P_{r m s}^{2}(f, \theta, \phi)_{\text {unshielded }}}=10^{\left(\frac{\Delta d B}{10}\right)}
$$

- Applied to engine source noise to account for installation effects due to

- Shielding / reflection from airframe

- Modification of source level and directivity due to change in flow field from free stream

Shielding is dependent on noise source characteristics and directivity, source/airframe positioning, airframe shape, control surface deflection, and frequency 


\section{Uncertainty Quantification of System Noise Prediction}

- Companion paper presents framework and process for establishing aircraft noise prediction uncertainty

- The uncertainty on EPNL prediction is computed in a direct Monte Carlo process

- 10,000 EPNL simulations: EPNL $_{\mathrm{i}}=f\left(\right.$ prediction element $\left._{\mathrm{i}}\right)$

- Source prediction elements: Engine (fan, jet, etc.), airframe (gear, etc.), PAA-effects

- New uncertainty framework/process outlines four methods for determination of prediction element uncertainty

I. Reference data prediction test method

II. Formulation method

III. Fixed by aircraft level method

IV. Inferred method

- Reference data prediction test method: "Reference Dataset" hierarchy

1. Full-scale, full-fidelity aircraft flight data

2. Model-scale, higher fidelity integrated system experimental data

3. Model-scale, high fidelity sub-system experimental data

4. Isolated component experimental data 


\section{Full-Scale Propulsion Airframe Aeroacoustic (PAA) "Reference Dataset"}

PAA integration effects from a similar engine installed on similar sized but different aircraft configurations - likely PAA effects are acoustic shielding by wing and fuselage for tail mount while the under-wing mounting increases noise from reflection and jet-flap interaction (Ron Olsen, Boeing)

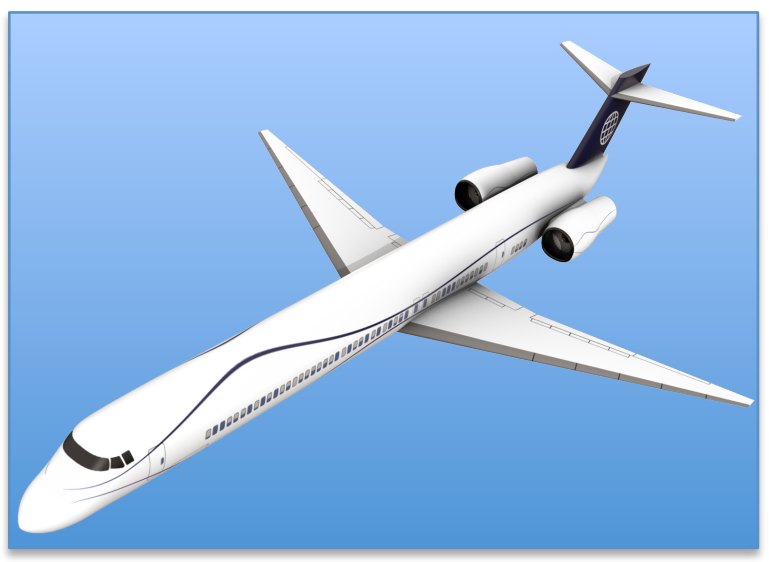

Boeing MD-90-30

Engine IAE 2528-D5

Thrust (lbs) 28,000

MTOW (lbs) 166,000

MLW (lbs) 142,000

Noise Certification (EPNdB):

Approach $\quad 91.9$

Lateral $\quad 91.0$

Flyover $\quad 82.6$

Cumulative Margin Relative to

Stage $3=-23.5$ EPNdB

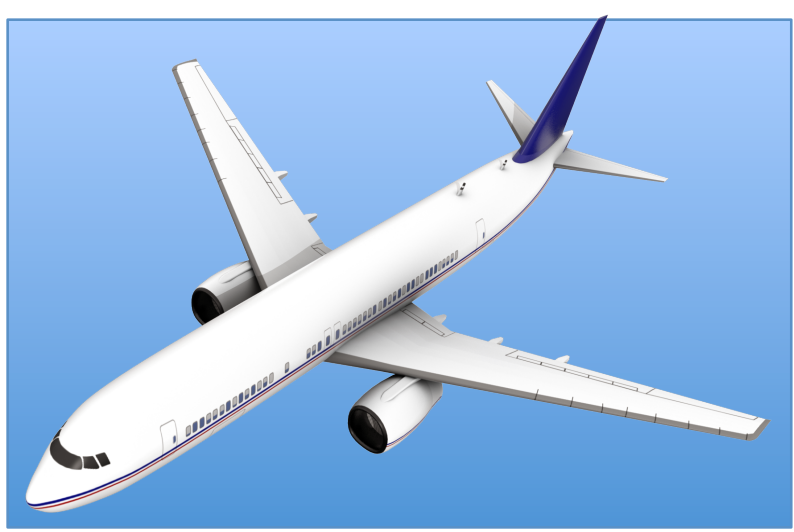

Airbus A319-133

Engine IAE 2527M-A5

Thrust (lbs) 26,500

MTOW (lbs) $\quad 166,400$

MLW (lbs) $\quad 137,800$

(relative to MD-90-30)

Approach

94.4

92.5

$+2.5$

Lateral

84.2

$+1.5$

$+1.6$

Cumulative Margin Relative to

Stage $3=-17.9$ EPNdB

$+5.6$ 


\section{Certification Noise Margins Relative to Stage 3}

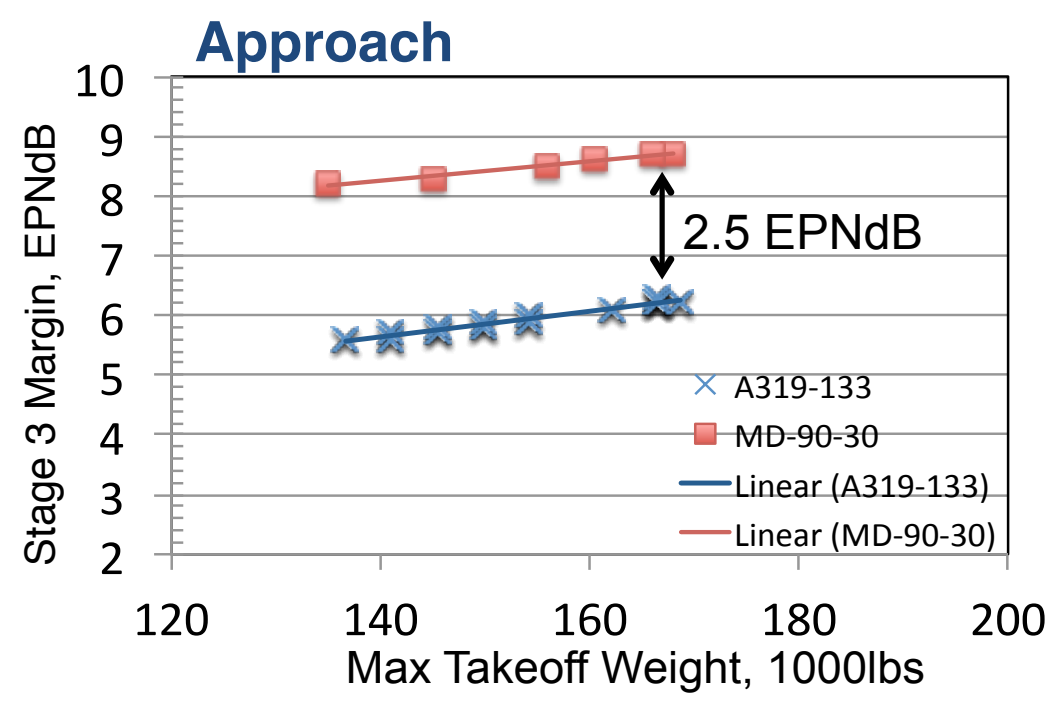

- Noise certification data (ref. EASA (European Aviation Safety Agency)

- Nearly linear function with Max Takeoff Weight

- Difference in EPNL invariant with MTOW
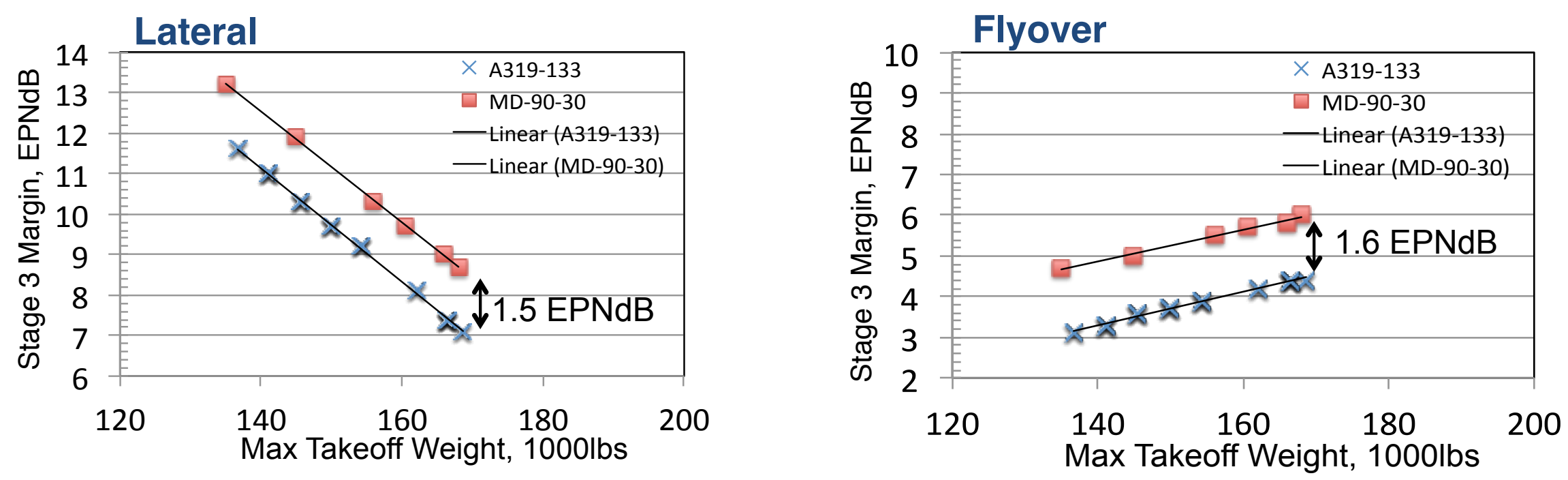


\section{PAA-Effect Prediction Uncertainty Process}

- Simulate configurations of MD-90-30 and A319-133 with NASA model of 737-800 with CFM56 engines

\begin{tabular}{|c|c|c|c|}
\hline & Boeing MD-90-30 & Airbus A319-133 & Boeing 737-800 \\
\hline $\begin{array}{l}\text { Engine/airframe } \\
\text { Configuration }\end{array}$ & $\begin{array}{l}\text { Empennage- } \\
\text { mounted }\end{array}$ & Under-the-wing & Under-the-wing \\
\hline Engine & IAE 2528-D5 & IAE 2527M-A5 & CFM56-7B \\
\hline Thrust & 28,000 & 26,500 & 26,000 \\
\hline BPR & 4.8 & 4.7 & 5.2 \\
\hline MTOW (Ibs) & 166,000 & 166,400 & 174,000 \\
\hline
\end{tabular}

- Predict PAA-effect for the both configurations

- Broadband engine noise scattering

- Jet noise scattering

- Compare difference in EPNL at each certification noise point to Reference Dataset differences

- Match Reference Dataset result by "adjusting" PAA-effect prediction 


\section{Noise Simulations of PAA Configurations}

- Engine represented by NPSS NASA model of CFM56-7B

- Airframe and certification flight path determined from FLOPS aeroperformance analysis of NASA 737-800 like aircraft

- Noise Scattering (PAA-effect) Prediction

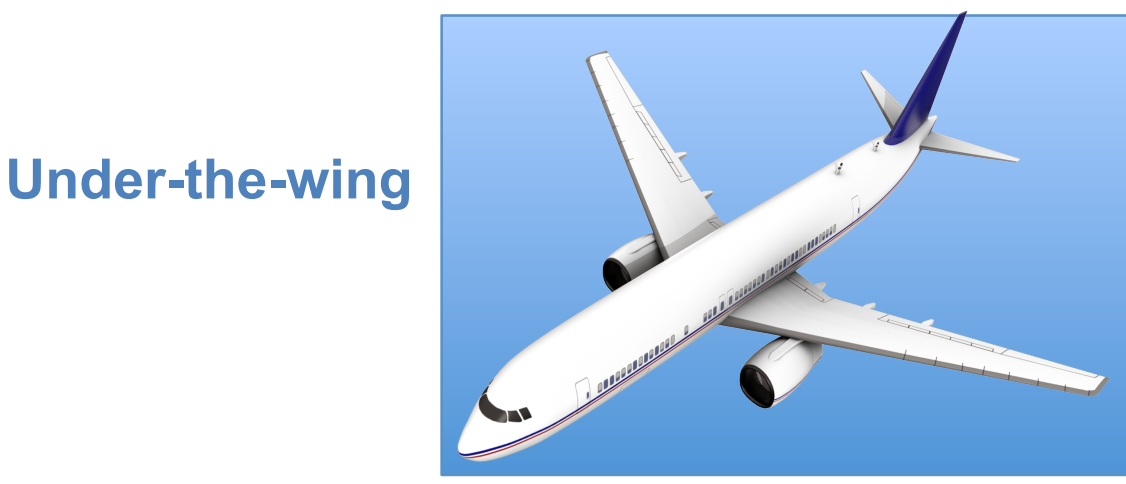

- Aft engine sources: wing reflection

- Jet: reflected from wing

- Observers directly in sight of both engines

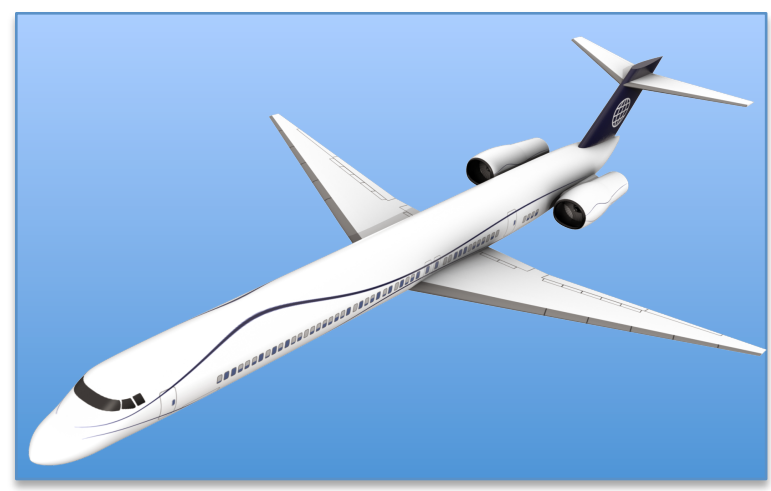

- Inlet engine sources: wing shielding

- Jet: reflected from horizontal tail

- Sideline observers: one engine shielded, but engine noise reflected from fuselage 


\section{Prediction Compared to Reference Dataset}

\begin{tabular}{|c|c|c|c|c|}
\hline & $\begin{array}{c}\text { Under-the-wing } \\
\text { engine }\end{array}$ & $\begin{array}{c}\text { Empennage- } \\
\text { mounted engine }\end{array}$ & $\begin{array}{c}\Delta \text { EPNL } \\
\text { Prediction }\end{array}$ & $\begin{array}{c}\Delta \text { EPNL } \\
\text { Reference } \\
\text { Dataset }\end{array}$ \\
\hline $\begin{array}{c}\text { Approach } \\
\text { (EPNdB) }\end{array}$ & 96.4 & 94.8 & 1.6 & 2.5 \\
\hline $\begin{array}{c}\text { Lateral } \\
\text { (EPNdB) }\end{array}$ & 95.1 & 91.4 & 3.7 & 1.5 \\
\hline $\begin{array}{c}\text { Flyover } \\
\text { (EPNdB) }\end{array}$ & 86.3 & 85.5 & 0.8 & 1.6 \\
\hline
\end{tabular}

- Discrepancy between $\triangle \mathrm{EPNL}$ results from prediction and Reference Dataset is indirect measure of prediction uncertainty

- Approach and Flyover: underprediction of shielding effect

- Lateral: overpredict noise shielding 


\section{Noise Scattering Prediction Map Adjustment $(\Delta \mathrm{SPL}, \mathrm{dB})$}

- Engine noise scattering prediction uncertainty

- Dependent on engine source, geometry, flight condition \& data available

- Representative jet source: nozzle geometries, flow and cycle conditions

- Turbomachinery (broadband) source: representative nacelle with "impinging-jet" source

- Empennage-mounted engine configuration PAA-effect prediction adjusted

- Uniformly applied spectrally at each polar and azimuthal directivity angle

- Lateral: reduced "shielding" effect

- Approach and Flyover: increased "shielding" effect

\begin{tabular}{|c|c|c|c|}
\hline $\begin{array}{c}\text { Engine Source/ } \\
\text { PAA map source }\end{array}$ & Approach & Lateral & Flyover \\
\hline $\begin{array}{c}\text { fan \& core / } \\
\text { Broadband (dB) }\end{array}$ & -1.0 & +3.3 & -1.5 \\
\hline Jet / Jet (dB) & 0.0 & +1.5 & 0.0 \\
\hline
\end{tabular}




\section{Predicted PNLT and EPNL With Adjusted Noise Scattering Maps}

\section{Lateral}

$\triangle \mathrm{EPNdB}=1.5$
Under-the-wing engines

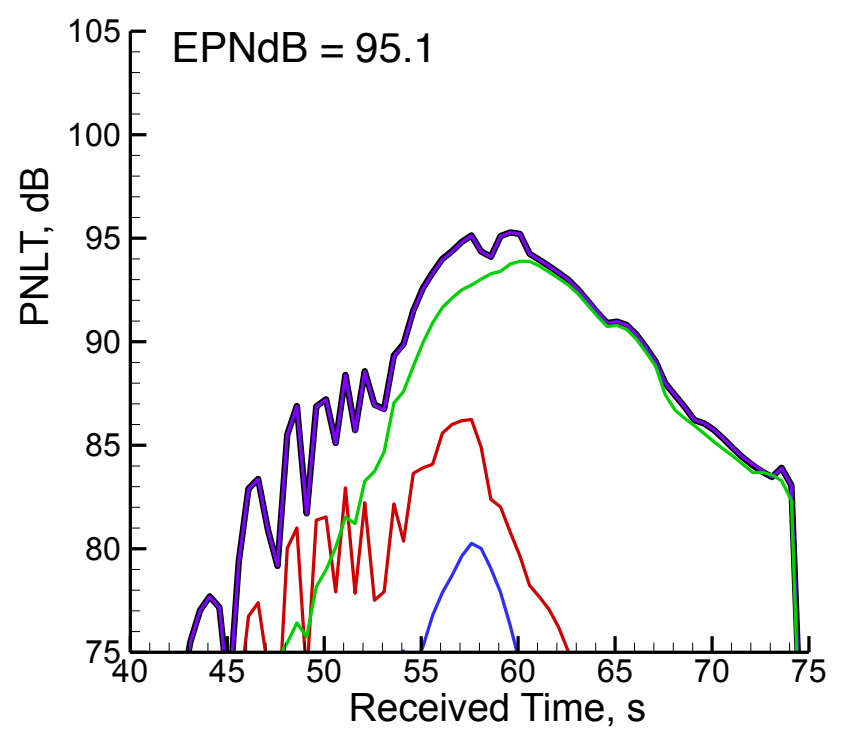

\section{Flyover}

$\triangle \mathrm{EPNdB}=1.6$

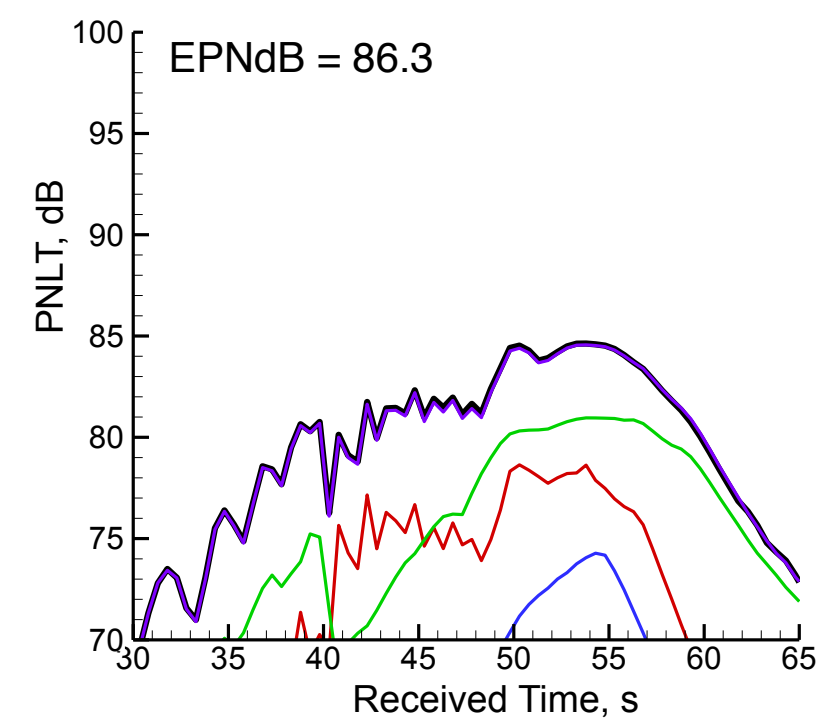

Empennage-mounted engines
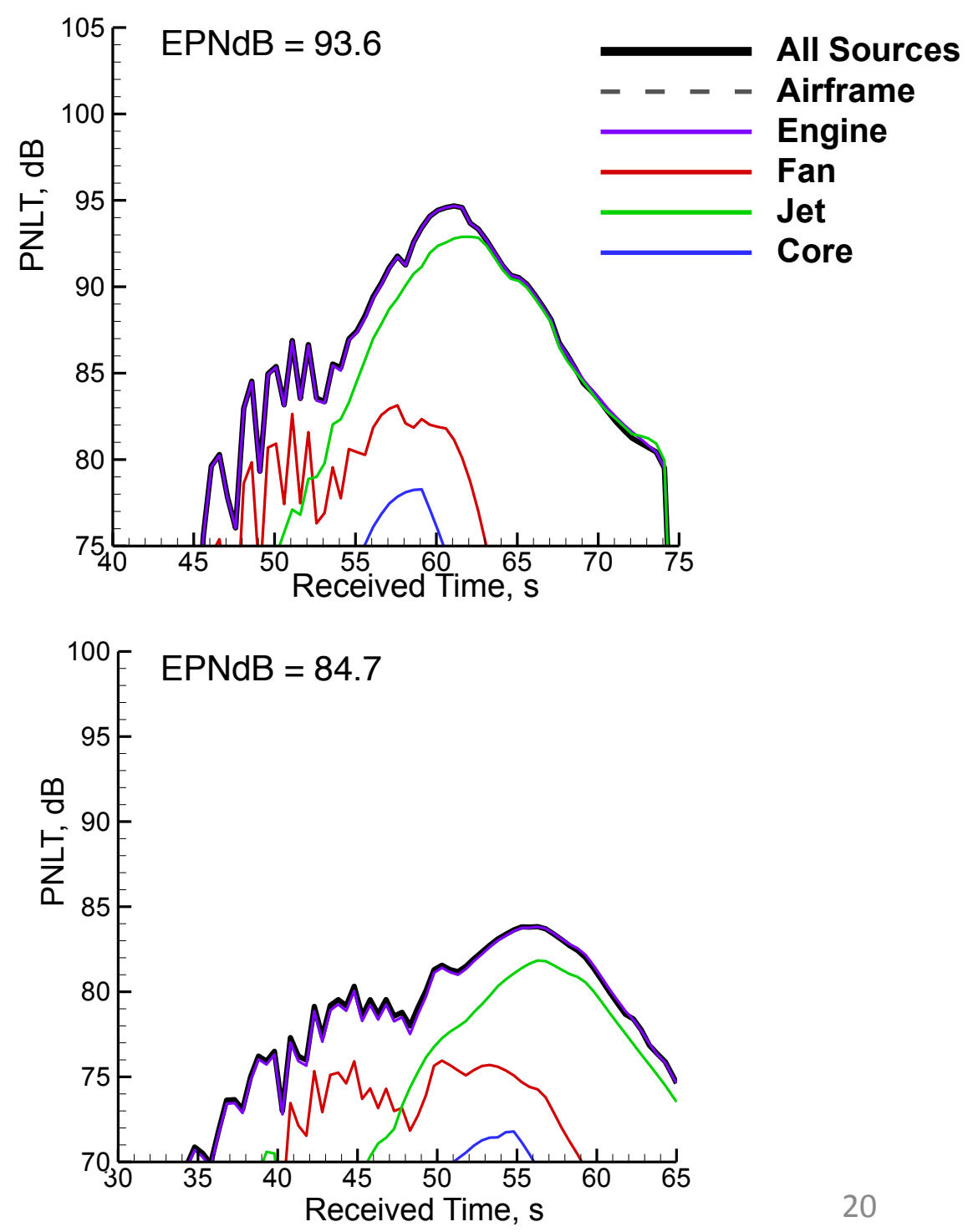


\section{Acoustic Scattering Prediction Uncertainty}

- Established through deductive inference and additional considerations

- If Reference Dataset quantifies the PAA-effect between aircraft configurations

- And the PAA-effect difference can be computed through simulation whereby only change is the engine noise scattering prediction

- Then the discrepancy between results from Reference Dataset and simulation is measure of prediction uncertainty

- Additional considerations include fidelity of PAA-effect prediction method datasets and modeling, and their range of validity for vehicles in flight

\begin{tabular}{|c|c|c|}
\hline $\begin{array}{c}\text { Engine Source/ } \\
\text { PAA map source }\end{array}$ & $\begin{array}{c}\text { 95\% Confidence } \\
\text { Level }\end{array}$ & $\begin{array}{c}\text { Standard } \\
\text { Deviation }\end{array}$ \\
\hline $\begin{array}{c}\text { Fan \& Core / } \\
\text { Broadband }(\mathrm{dB})\end{array}$ & \pm 4 & 2 \\
\hline Jet / Jet $(\mathrm{dB})$ & \pm 2 & 1 \\
\hline
\end{tabular}




\section{Concluding Remarks}

- Described a process to quantify the uncertainty of the "acoustic scattering prediction element" utilized in full-scale, full-fidelity aircraft system noise simulations

- Scattering prediction element uncertainty quantified using the "Reference data prediction test method" with full-scale, full-fidelity aircraft flight data

- Quantification of the "acoustic scattering prediction element" is a valuable contribution to establishing aircraft noise prediction uncertainty for both conventional and unconventional configurations.

- Acoustic scattering prediction uncertainty can be improved, particularly for installed turbomachinery sources, through dedicated campaigns:

- Higher fidelity flight acoustic "Reference Dataset"

- Large-scale wind tunnel PAA tests with representative source

- Development and validation of physics-based computational methods 


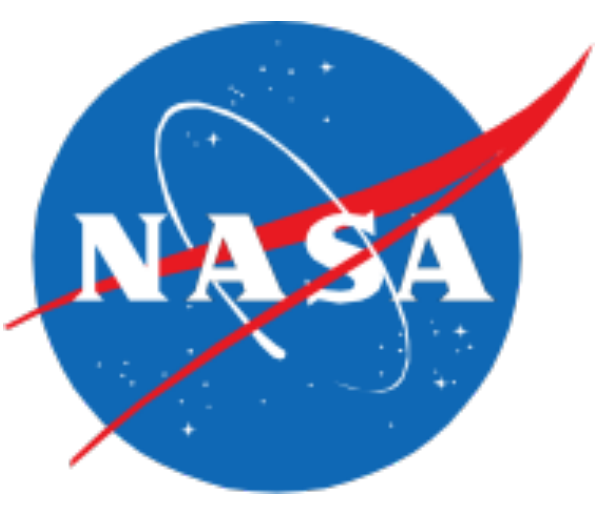

